2. Sakkas LI, Zafiriou E, Bogdanos DP. Mini Review: New Treatments in Psoriatic Arthritis. Focus on the IL-23/17 Axis. Front Pharmacol 2019:10:872.

3. Larosa M, Zen M, Gatto M, et al. IL-12 and IL-23/Th17 axis in systemic lupus erythematosus. Exp Biol Med (Maywood) 2019;244(1):42-51.

\section{NOVEL INTRACELLULAR PATHWAYS}

Thomas Dörner. Charite University Hospitals Berlin, Germany

\subsection{6/lupus-2020-la.9}

Systemic lupus erythematosus (SLE) is a heterogeneous disease characterised by abnormalities in cellular and humoral immunity. Here disturbances in cytokine production and B lineage cell disturbances became very evident in recent years. Identification of increased interleukin (IL)-6, IL-17, IL-12 and IL-23, BAFF, and especially type I interferon (IFN) production by different cell types, provided the rationale for targeting these cytokines or their corresponding cytokine receptors using biologics. Since these cytokines activate various intracellular pathways, such as Jak/Stat signaling, activation of the $\mathrm{Nf} \kappa \mathrm{B}$ or using spleen tyrosine kinase (Syk), Bruton's tyrosine kinase (BTK), small molecules inhibiting these pathways are being investigated in various clinical studies.

It should be emphasised that most of the above-mentioned intracellular pathways may vary between different immune cells and tissues and can have interactions which have not been fully described. However, certain strategies target multiple key pathways along with inhibiting various cytokines (multiple targeting therapy), ${ }^{1}$ which holds the promise to cover broadly heterogeneous SLE, a therapeutic principle that has already been introduced in other disciplines, such as antihypertensive and anti-infectious treatment algorithms.

As a first example in patients with SLE, treatment with the Jak1/Jak2 blocking agent (jakinib) baricitinib showed improvements of skin and joint manifestations among patients with a daily dose of $4 \mathrm{mg} / \mathrm{d}$ but less pronounced under $2 \mathrm{mg} / \mathrm{d}$ in a Phase II trial over 24 weeks. ${ }^{2}$ Another Phase $\mathrm{Ib} / \mathrm{IIa}$ trial using tofacitinib as Jak1/Jak3 selective inhibitor in SLE has been reported without substantial safety concerns and early signs of efficacy. $^{3}$ In addition to jakinib in studies with SLE, there are also trials of inhibitors of other pathways (BTK ${ }^{4}$, Syk etc.) that hold promise for a new era of more efficacious and welltolerated therapies, which may address the current and substantial need for the effective treatment of SLE. Of note, recent Phase 2 data of the BTK inhibitor fenebrutinib (GDC0853) targeting B cells, monocytes and mast cells did not demonstrate differentiating efficacy in general $\mathrm{SLE}^{4}$. While this is an unexpected but interesting finding, targeting BTK in SLE needs to be further explored based on convincing efficacy of the BTK inhibitor evobrutinib in relapse-remitting multiple sclerosis. $^{5}$

\section{Learning Objectives}

- Discuss the potential for novel therapeutic targets in SLE

- Explain the significance of certain signaling pathways with a particular focus on Jak/Stat system and current treatment developments in SLE

\section{REFERENCES}

1. Dorner T, Furie R. Novel paradigms in systemic lupus erythematosus. Lancet (London, England) 2019;393(10188):2344-58. doi: 10.1016/s0140-6736(19)30546-x
2. Wallace DJ, Furie RA, Tanaka Y, et al. Baricitinib for systemic lupus erythematosus: a double-blind, randomised, placebo-controlled, phase 2 trial. Lancet (London, England) 2018;392(10143):222-31. doi: 10.1016/s0140-6736(18)31363-1

3. Hasni S. A Phase 1b/2a Trial of Tofacitinib, an Oral Janus Kinase Inhibitor, in Systemic Lupus Erythematosus. 13th World Congress on SLE, San Francisco April 3rd, 2019. Oral presentation.

4. Isenberg D, Furie $R$, Jones NS, et al. OP0233 EFFICACY, SAFETY, AND PHARMACODYNAMIC EFFECTS OF THE BRUTON'S TYROSINE KINASE INHIBITOR, FENEBRUTINIB (GDC-0853), IN MODERATE TO SEVERE SYSTEMIC LUPUS ERYTHEMATOSUS IN A PHASE 2 CONTROLLED STUDY. Ann Rheum Dis 2020;79 (Suppl 1):148-48.

5. Montalban X, Arnold DL, Weber MS, et al. Placebo-Controlled Trial of an Oral BTK Inhibitor in Multiple Sclerosis. N Engl J Med 2019;380(25):2406-17.

\section{MOLECULES IN EARLY DEVELOPMENT}

Richard Furie. Zucker School of Medicine at Hofstra/Northwell, New York, USA

\subsection{6/lupus-2020-la.10}

'Eclectic', what a great word to describe the approaches to the development of drugs in systemic lupus erythematosus (SLE)! 'Eclectic' comes from a Greek verb meaning 'to select' and was originally applied to ancient philosophers who were not committed to any single system of philosophy; instead, these philosophers selected whichever doctrines pleased them from every school of thought. ${ }^{1}$ Much like the ancient Greek philosophers, drug target selection in SLE has spanned many pathways. Although belimumab has been the sole drug approved to date via the traditional route of a randomised controlled trial, it's just a matter of time before drugs targeting other molecules and pathways are granted approval for SLE and lupus nephritis.

The potential drug targets in SLE appear limitless, making decisions regarding resource allocation incredibly challenging. Should components of the innate or the adaptive immune system be targeted? Perhaps both? This presentation will review various strategies being pursued in order to inhibit key pathways in SLE. The emphasis will be on investigational agents in Phase I and Phase II programmes. ${ }^{2-7}$

\section{Learning Objectives}

- Describe strategies for inhibiting the type I interferon pathway

- Discuss methods to target B and T cells

- Review approaches to down-regulate pro-inflammatory cytokines

\section{REFERENCES}

1. Merriam-Webster Unabridged accessed June 19, 2020.

2. Furie R, Werth VP, Merola JF, et al. Monoclonal antibody targeting BDCA2 ameliorates skin lesions in systemic lupus erythematosus. J Clin Invest 2019:129 (3):1359-71.

3. Furie R, Aroca G, Alvarez A, et al. A Phase II Randomized, Double-Blind, Placebo-Controlled Study to Evaluate the Efficacy and Safety of Obinutuzumab or Placebo in Combination with Mycophenolate Mofetil in Patients with Active Class III or IV Lupus Nephritis [abstract]. Arthritis Rheumatol 2019;71 (Suppl. 10).

4. Isenberg $D$, Furie $R$, Jones $N$, et al. Efficacy, Safety, and Pharmacodynamic Effects of the Bruton's Tyrosine Kinase Inhibitor, Fenebrutinib (GDC-0853), in Moderate to Severe Systemic Lupus Erythematosus: Results of a Phase 2 Randomized Controlled Trial [abstract]. Arthritis Rheumatol 2019;71 (Suppl. 10).

5. Papp K, Gordon K, Thaçi D, et al. Phase 2 Trial of Selective Tyrosine Kinase 2 Inhibition in Psoriasis. N Engl J Med 2018:379(14):1313-21.

6. Furie R, Bruce I, Dörner $T$, et al. Efficacy and Safety of Dapirolizumab Pegol in Patients with Moderately to Severely Active Systemic Lupus Erythematosus: A Randomized, Placebo-Controlled Study [abstract]. Arthritis Rheumatol 2019;71 (Suppl. 10)

7. Basta F, Fasola F, Triantafyllias K, et al. Systemic Lupus Erythematosus (SLE) Therapy: The Old and the New. Rheumatol Ther 2020 doi: 10.1007/s40744-02000212-9 [published Online First: 2020/06/04]. 